\title{
M-protein and other intrinsic virulence factors of Streptococcus pyogenes are encoded on an ancient pathogenicity island
} Alexandre Panchaud ${ }^{\dagger 1,2}$, Lionel Guy ${ }^{\dagger 1,3}$, François Collyn ${ }^{1,4}$, Marisa Haenni ${ }^{1,5}$, Masanobu Nakata6,7, Andreas Podbielski ${ }^{6}$, Philippe Moreillon ${ }^{* 1}$ and ClaudeAlain H Roten ${ }^{1}$

Address: ${ }^{1}$ Department of Fundamental Microbiology, University of Lausanne, Quartier UNIL-Sorge, Bâtiment Biophore, CH-1015 Lausanne, Switzerland, ${ }^{2}$ Department of Medicinal Chemistry, University of Washington, Seattle, WA, USA, ${ }^{3}$ Molecular Evolution, Uppsala University, Norbyvägen 18C, 75236 Uppsala, Sweden, ${ }^{4}$ Institute of Microbiology, University Hospital Center and University of Lausanne, Bugnon 48, CH1011 Lausanne, Switzerland, ${ }^{5}$ Agence Française de Sécurité Sanitaire des Aliments (Afssa), Avenue Tony Garnier 31, 69007 Lyon, France, ${ }^{6}$ Deptartment of Medical Microbiology, Virology \& Hygiene, Univ. Hospital, Schillingallee 70, D-18057 Rostock, Germany and ${ }^{7}$ Dept. of Oral and Molecular Microbiology, Osaka University Graduate School of Dentistry, 1 - 8, Yamadoaka, Suita-Osaka 565-0871, Japan

Email: Alexandre Panchaud - panchaud@u.washington.edu; Lionel Guy - lionel.guy@ebc.uu.se; François Collyn - francois.collyn@chuv.ch; Marisa Haenni - m.haenni@lyon.afssa.fr; Masanobu Nakata - masanobu.nakata@med.uni-rostock.de;

Andreas Podbielski - andreas.podbielski@med.uni-rostock.de; Philippe Moreillon* - philippe.moreillon@unil.ch; Claude-

Alain H Roten - claudealainroten@gmail.com

* Corresponding author †Equal contributors

Published: 27 April 2009

BMC Genomics 2009, 10:198 doi:10.1186/147/-2164-10-198

This article is available from: http://www.biomedcentral.com//47/-2/64//10/198

(C) 2009 Panchaud et al; licensee BioMed Central Ltd.

This is an Open Access article distributed under the terms of the Creative Commons Attribution License (http://creativecommons.org/licenses/by/2.0), which permits unrestricted use, distribution, and reproduction in any medium, provided the original work is properly cited.
Received: 4 December 2008

Accepted: 27 April 2009

\begin{abstract}
Background: The increasing number of completely sequenced bacterial genomes allows comparing their architecture and genetic makeup. Such new information highlights the crucial role of lateral genetic exchanges in bacterial evolution and speciation.

Results: Here we analyzed the twelve sequenced genomes of Streptococcus pyogenes by a naïve approach that examines the preferential nucleotide usage along the chromosome, namely the usage of G versus C (GC-skew) and T versus $A$ (TA-skew). The cumulative GC-skew plot presented an inverted V-shape composed of two symmetrical linear segments, where the minimum and maximum corresponded to the origin and terminus of DNA replication. In contrast, the cumulative TA-skew presented a V-shape, which segments were interrupted by several steep slopes regions (SSRs), indicative of a different nucleotide composition bias. Each S. pyogenes genome contained up to nine individual SSRs, encompassing all described strain-specific prophages. In addition, each genome contained a similar unique non-phage SSR, the core of which consisted of $3 \mathrm{I}$ highly homologous genes. This core includes the M-protein, other mga-related factors and other virulence genes, totaling ten intrinsic virulence genes. In addition to a high content in virulence-related genes and to a peculiar nucleotide bias, this SSR, which is $47 \mathrm{~kb}$-long in a MIGAS strain, harbors direct repeats and a tRNA gene, suggesting a mobile element. Moreover, its complete absence in a M-protein negative group A Streptococcus natural isolate demonstrates that it could be spontaneously lost, but in vitro deletion experiments indicates that its excision occurred at very low rate. The stability of this SSR, combined to its presence in all sequenced S. pyogenes sequenced genome, suggests that it results from an ancient acquisition.
\end{abstract}

Conclusion: Thus, this non-phagic SSR is compatible with a pathogenicity island, acquired before S. pyogenes speciation. Its potential excision might bear relevance for vaccine development, because vaccines targeting M-protein might select for M-protein-negative variants that still carry other virulence determinants. 


\section{Background}

Bacteria undergo constant mutations and horizontal gene transfer that help them compete in particular ecological niches. Genetic elements can be transferred on DNA stretches, within viruses, or by intercellular contacts. For example, bacteriophages carrying toxin genes can be inserted into bacterial chromosomes and re-program Streptococcus pyogenes to produce streptococcal toxic shock syndrome [1,2], or Staphylococcus aureus to express Panton-Valentine toxin [3]. Likewise, plasmids and pathogenicity islands can transform non-pathogenic Escherichia coli into virulent enteropathogenic (EPEC) or enterohemorrhagic (EHEC) strains [4-6]. Thus, horizontal gene transfer is critical for bacterial genome evolution, and includes genes for virulence, antibiotic resistance and metabolic features [7-9]. Objective criteria have been established to detect them, especially pathogenicity island: presence of virulence-related genes, location on the chromosome, different $\mathrm{G}+\mathrm{C}$ content, direct repeats on the flanks, association with a tRNA, presence of mobility genes (integrases, transposases, insertion sequences), ability to be mobilized, site-specific integration [10].

When mobile elements confer an advantage to the recipient, they promote its clonal expansion and may become stabilized in the bacterial host. This is illustrated by the insertion of SCC mec (staphylococcal cassette chromosome) into the $S$. aureus chromosome, generating methicillin-resistant $S$. aureus (MRSA) [11-13] which successfully expanded in the hospital and recently in the community [14]. However, when all bacteria of the same type share a similar mobile element, its acquired nature may pass unnoticed. It may ultimately become a taxonomic criterion, thus blurring the history of horizontal gene transfer that shaped important pathogens.

Genome analysis by bioinformatics helps highlight such issues. The approach stands on the fact that the genome architecture differs in distinct living organisms, including at the gene level, the $\mathrm{G}+\mathrm{C}$ content, the codon usage, and/ or more subtle biases in nucleic acid arrangements [15]. Nevertheless, bioinformatic methodologies present limitations. For instance, when a foreign element is shared by most of the strains, the comparison of the gene content of these strains will not identify this element as foreign. Likewise, comparing $\mathrm{G}+\mathrm{C}$ contents between the core chromosome and a putative mobile element is inconclusive when the recipient's chromosome and the mobile element shared a similar $\mathrm{G}+\mathrm{C}$ content at the time of the horizontal transfer, or when the $\mathrm{G}+\mathrm{C}$ content of the mobile element has progressively adapted to that of the recipient, a process called homing [10]. Acquired elements may also be identified by the presence of relics of prophages or DNA mobilization signatures in the core chromosome - e.g. integrases, excisases, or the presence of direct repeats or tRNA genes at the border of the element. However, such signatures might gradually become cryptic by amelioration occurring during island stabilization [16].

The present study uses a naïve approach, called "cumulative TA skew" [17-20] to seek the presence of foreign genetic elements in the genomes of the twelve currently completely sequenced $S$. pyogenes strains (Table 1 ). This method measures the local nucleotide usage without any a priori on nucleotide composition of DNA sequences. It can differentiate between DNA segments that slightly favor different nucleotide usage. Such approach was developed in cryptography and linguistics [21], enabling for instance to spot an English paragraph within a French text, knowing that English spelling favors the use of the digram "th". Such non a priori approaches, based on letter/nucleotide usage, do not need any information of word/codon, grammar/structure or style/genome to identify pattern differences.

This simple genometric analysis or genome biometrics unambiguously identified all the described S. pyogenes prophages, which differed from the core chromosome

Table I: Completely sequenced strains of Streptococcus pyogenes used in this study. M protein type, size, number of SSRs, associated diseases, accession number as well as references are summarized.

\begin{tabular}{|c|c|c|c|c|c|c|c|}
\hline Index & Strain & M-protein type & Size, bp & SSRs & Accession number & Associated disease & Reference \\
\hline I & SF370 & I & $\mathrm{I}, 852,44 \mathrm{I}$ & 5 & [GenBank:NC 002737] & Pharyngitis and invasive disease & {$[26]$} \\
\hline 2 & MGAS5005 & I & $\mathrm{I}, 838,554$ & 4 & [GenBank:NC 007297] & Sepsis and meningitis & {$[44]$} \\
\hline 3 & MGASI0270 & 2 & $1,928,554$ & 6 & [GenBank:NC 008022] & & [36] \\
\hline 4 & MGAS3I5 & 3 & $1,900,521$ & 7 & [GenBank:NC 004070] & Streptococcal toxic shock syndrome & [37] \\
\hline 5 & SSI-I & 3 & $1,894,275$ & 7 & [GenBank:NC 004606] & & [39] \\
\hline 6 & MGASI0750 & 4 & $1,937,111$ & 6 & [GenBank: & & [36] \\
\hline 7 & Manfredo & 5 & $|, 84|, 27 \mid$ & 6 & [GenBank:NC 009332] & Acute rheumatic fever & [4I] \\
\hline 8 & MGASI0394 & 6 & I,899,877 & 9 & [GenBank:NC 006086] & & [27] \\
\hline 9 & MGAS2096 & 12 & $1,860,355$ & 4 & [GenBank:NC 008023] & Pharyngitis & [36] \\
\hline 10 & MGAS9429 & 12 & $1,836,467$ & 4 & [GenBank:NC 00802I] & & [36] \\
\hline 11 & MGAS8232 & 18 & $1,895,017$ & 6 & [GenBank:NC 003485] & Acute rheumatic fever & [40] \\
\hline 12 & MGAS6I80 & 28 & $\mathrm{I}, 897,573$ & 6 & [GenBank:NC 007296] & Puerperal sepsis & [29] \\
\hline
\end{tabular}


and were variously distributed in the twelve sequenced chromosomes (Table 1 ). Moreover, it revealed an additional unique divergence region $47-\mathrm{kb}$ in average (varying from 39 to $53 \mathrm{~kb}$ in the different strains), which is conserved in all sequenced strains, and encodes major intrinsic $S$. pyogenes virulence factors, including M-protein and the mga-virulon [1,22-24]. It also fairly complies with Hacker's criteria for a pathogenicity island [7-9]. Thus, Mprotein belongs to a large pathogenicity island that was probably acquired before the $S$. pyogenes speciation. Its potential instability could have practical implications for species identification in the clinical laboratory. Moreover, since $M$-protein is a vaccine target, the question arises as to whether anti-M-protein vaccines might select for escape variants lacking $M$-protein.

\section{Results}

S. pyogenes cumulative nucleotide skews

Fig. 1 presents the cumulative GC- and TA-skew curves of $S$. pyogenes M1 SF370. As represented in the insets, prokaryo-

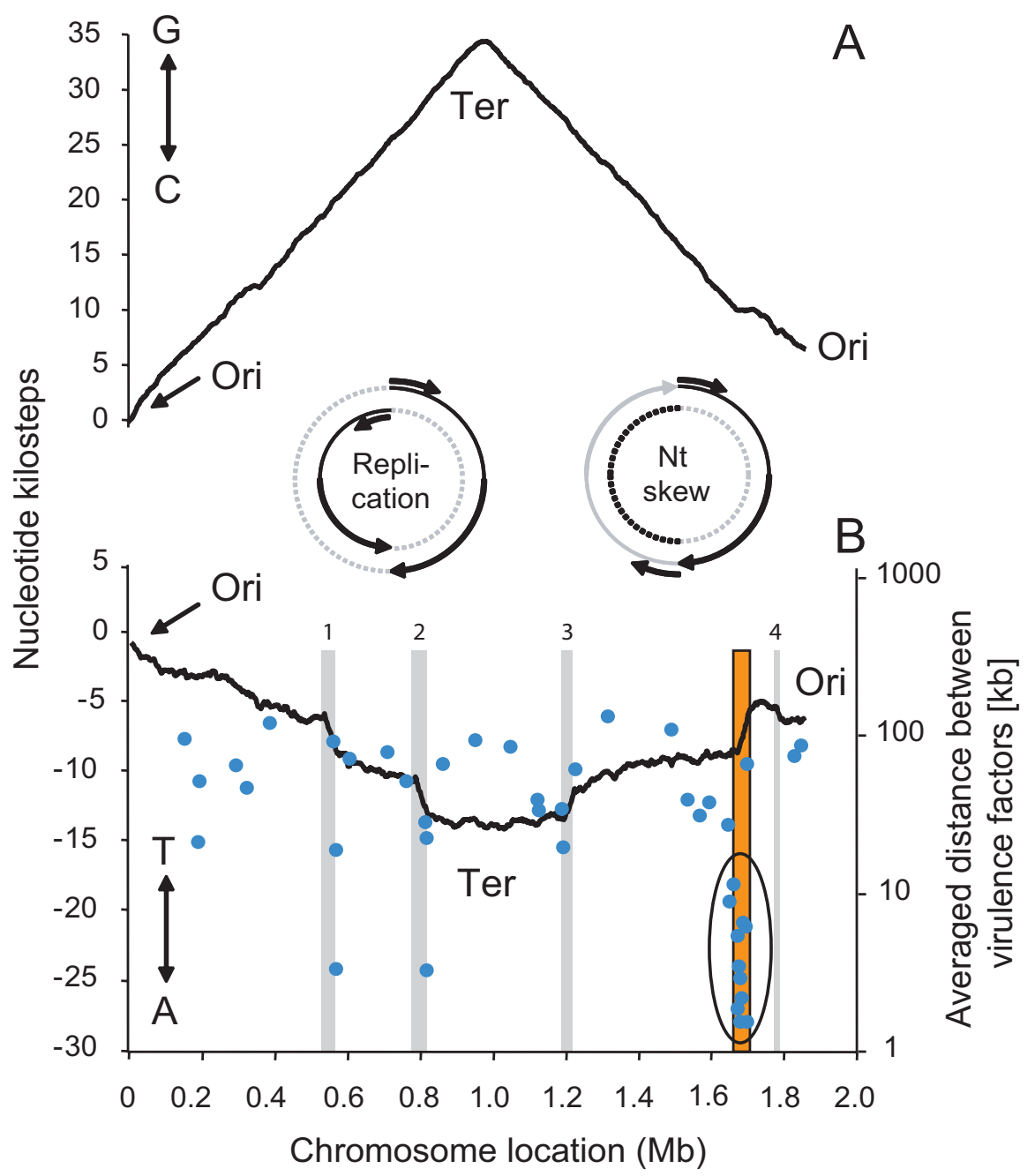

Figure I

Cumulative GC skew (A) and TA skew (B) of the chromosome of the MI S. pyogenes SF370. Cumulative skews ( $Y$-axis, in nucleotide kilosteps) are represented along the chromosome (X-axis). Both skews are performed on one of the two strand of the streptococcal DNA double helix. The TA skew (B) reveals segments with steeper slopes referred to as steepslope segments (SSRs) and revealing regions with different nucleotide composition. Phagic SSRs are represented by grey rectangles and numbered as they appear on the chromosome, while the conserved non-phagic SSR is outlined by a boxed orange rectangle. Virulence genes (blue dots) are spotted according to their position on the chromosome and the distance to the next virulence gene (right $Y$-axis, logarithmic scale). The overall average distance between virulence genes is $54.8 \mathrm{~kb}$, except for a group of 10 genes (circled) present in the non-phagic 47-kb SSR for which the average distance is only $4.3 \mathrm{~kb}$. This represents a ten-fold greater concentration of virulence factors compared to the rest of the chromosome. 
tes present a bidirectional replication starting from the origin of replication and reading in both directions until reaching a terminus (replication inset). The bidirectional replication therefore defines a leading and a lagging strand in the double helix. In the contrary, nucleotide sequence reading (nt skew inset) is unidirectional, starting from the origin of replication, passing through the terminus and finishing at the origin again (nt skew inset). The cumulative GC-skew (Fig. 1A) is composed of two symmetrical linear segments defined by the origin and the terminus of DNA replication corresponding to the minimum and the maximum of the curve respectively $[19,25]$ (see also Comparative Genometrics [20]). The positive or ascending slope reveals that this part of the chromosome sequence is enriched in guanine residues, whereas the negative or descending slope means that it is enriched in cytosine residues. This symmetric architecture relies on the almost universal bidirectional DNA replication and circular nature of the bacterial chromosome (inset in Fig. 1).

The cumulative GC-skews of the other eleven S. pyogenes chromosomes are similar to that shown in Fig. 1A (data not presented). In contrast, the cumulative TA-skews are quite different both in terms of smoothness and in interstrain variability (Fig. 1B and Fig. 2). Although both chromosomal arms conserve their symmetry, their slopes are opposite in TA- and GC-skews. Moreover, the two segments of the TA skew curves are interrupted by segments of steeper slopes, referred to as steep-slopes regions (SSR). These SSRs identify regions exhibiting different nucleotide composition than the core genome, and thus may highlight DNA segments of different origins.

\section{Genetic content of the SSRs in S. pyogenes MI SF370}

The cumulative TA-skew of strain SF370 contains five major SSRs (Fig. 1B). The nucleotide sequence of four of them corresponds to the four prophages $(370.1,370.2,370.3$ and 370.4) described in this strain [26]. The fifth SSR is a $47-\mathrm{kb}$ segment consisting of 40 ORFs (Additional file 1), of which $10(25 \%)$ code for $S$. pyogenes intrinsic virulence factors, including M-protein and part of the mga virulon $[1,22,23]$. The other $30(75 \%)$ code for determinants not known to be involved in pathogenicity, but including features compatible with an ancient mobile elements [10], such as a transposase gene (spy2013), two 11-bp direct repeats (starting at positions 1663812 and 1710243), and the vicinity of Lys-tRNA gene as a putative insertion/excision site. Fig. 1B also presents the distribution of the putative $S$. pyogenes virulence genes along the SF370 chromosome. Out of 43 virulence genes [26], 10 (24\%) are concentrated in the 47-kb SSR, 9 $(21 \%)$ are located within prophages, and 24 (55\%) are scattered along the rest of the genome. Thus, the density of virulence genes in the $47-\mathrm{kb}$ SSR (one virulence gene/4.3 kb) is 10 -fold higher than in the rest of the chromosome (one virulence gene $/ 54.8 \mathrm{~kb}$ ), further suggesting a pathogenicity island [7-9].

\section{Cumulative TA skews of the other sequenced S. pyogenes chromosomes}

Fig. 2 depicts the cumulative TA-skews of the twelve sequenced $S$. pyogenes chromosomes. All cumulative TAskews display the expected V-shape. In addition, each chromosome presents a unique set of SSRs located at various positions, except for the non-phagic 47-kb SSR whose position is conserved, but whose size varies from 39 to $53 \mathrm{~kb}$. The SSRs located at various places identify the strain-specific prophages already described in S. pyogenes (Fig. 2 and Fig. 3). They also spot the composite prophage-transposon chimera carrying an erythromycin-resistance marker and the R6 protein specific to sore-throat $S$. pyogenes M6 strains [27] (phage 4 of MGAS10394 on Fig. 2), as well as the 37.4$\mathrm{kb}$ region of RD2 recently reported in the chromosome of S. pyogenes M28, responsible of the puerperal fever $[28,29]$ (see MGAS6180 on Fig. 2). Other SSRs that are not described as prophages, but resemble mobile elements, are also present in the genomes of MGAS10750 (M4) and MGAS2096 (M12) (Fig. 2).

Since the $47-\mathrm{kb}$ SSR is shared by all the strains, we further analyzed the amino acid variations of this element by comparing protein sequences of strain SF370 to those of the eleven other sequenced strains (Table 1). The 47-kb SSR consists of a Lys-tRNA gene and a core of 31 ORFs, plus a few additional genes which vary between the organisms (Additional file 1). The 31 core gene products showed a high similarity ( $\geq 90 \%$ protein similarity), with the notorious exception for the variable M-protein (42\%) (Fig. 4) [30,31]. This is expected because the sequenced isolates represent different M-protein serotypes.

Thus, the genometric analysis identified all the horizontally-acquired $S$. pyogenes prophages, plus a unique nonphagic SSR compatible with a pathogenicity island. For comparison, the $\mathrm{G}+\mathrm{C}$ content analysis did not detect any of these elements (Fig. 5).

\section{Detection of spontaneous loss of the 47-kb SSR}

Since the M-protein-containing 47-kb SSR might represent a horizontally acquired element, we sought both whether natural group A streptococci missing this segment might exist, and whether it could be lost from S. pyogenes grown in vitro. A natural isolate of M-proteinnegative group A streptococcus (serotype T11) [32] was analyzed. PCR-amplification indicates that this strain lacks a large $43-\mathrm{kb}$ region, which encompasses $92 \%$ of the 47-kb SSR as determined by its genometric boundaries (Additional file 1 and Fig. 6).

Spontaneous deletion was sought by PCR-amplification of the whole 47-kb SSR from genomic DNA prepared from liquid cultures of reference strain SF370. In two out of four individual cycled cultures, an amplicon compatible with the excision of most part of the 47-kb SSR was 


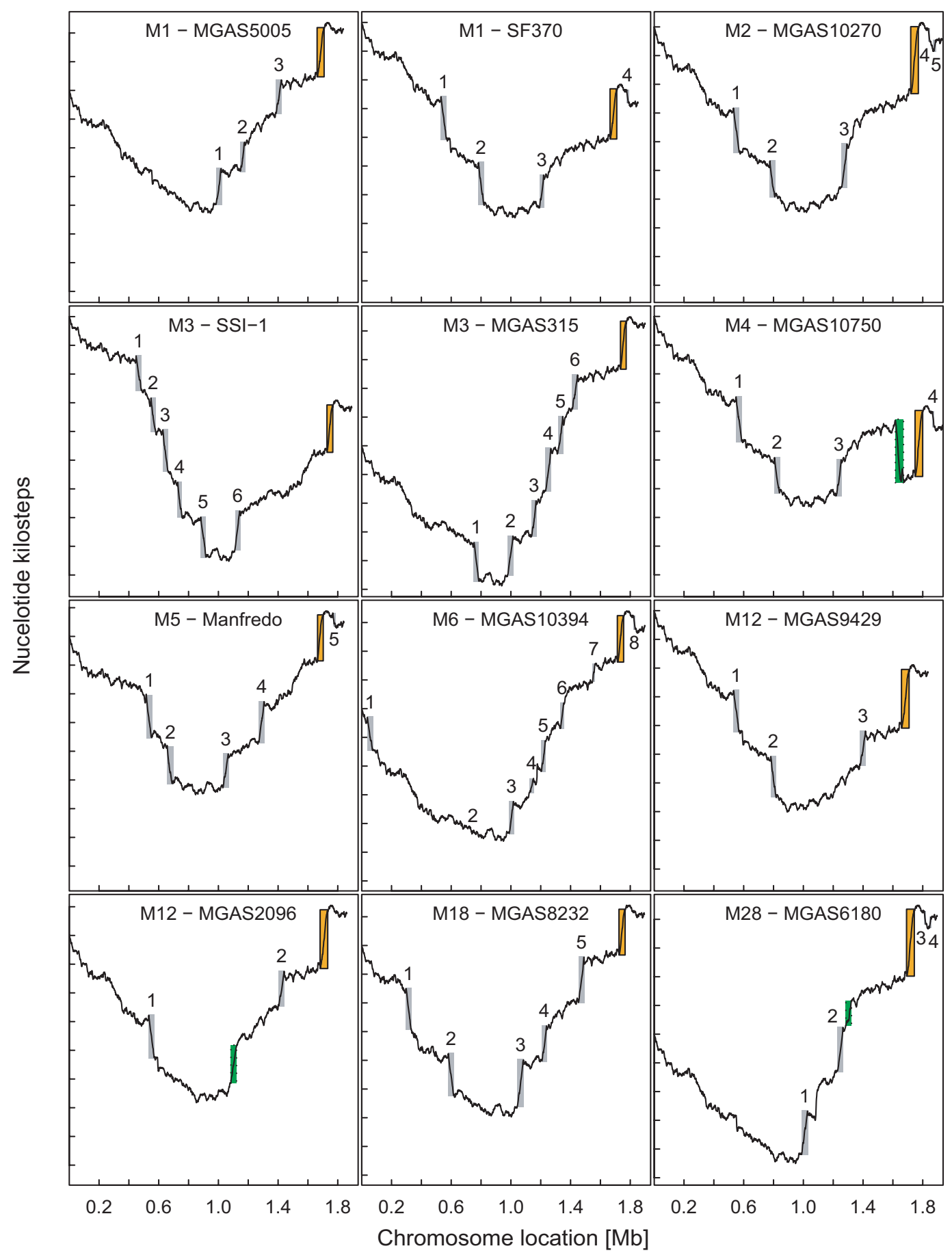

Figure 2

TA skews (as in Fig. I) for the twelve available genomes of $S$. pyogenes (see Table I). Each tick mark on the vertical axes indicates 2000 T over A excess. Phagic SSRs are represented by grey rectangles while the conserved non-phagic SSR is outlined by boxed orange rectangles. In MGAS2096, MGAS6I80 and MGASI0750, peculiar regions not documented as phages and presenting a different TA skew are shown with a green dotted box. These three regions are discussed in the text. Eventually, SSRs that are not described as prophages, but resemble mobile elements, are also present in the genomes of MGASI0750 and MGAS2096 and are the purpose of further studies. Phage numbering follows the order on the chromosome: in MGAS9429, I stands for phage 9429.I, 2 stands for phage 9429.2, etc (see references in Table I). 


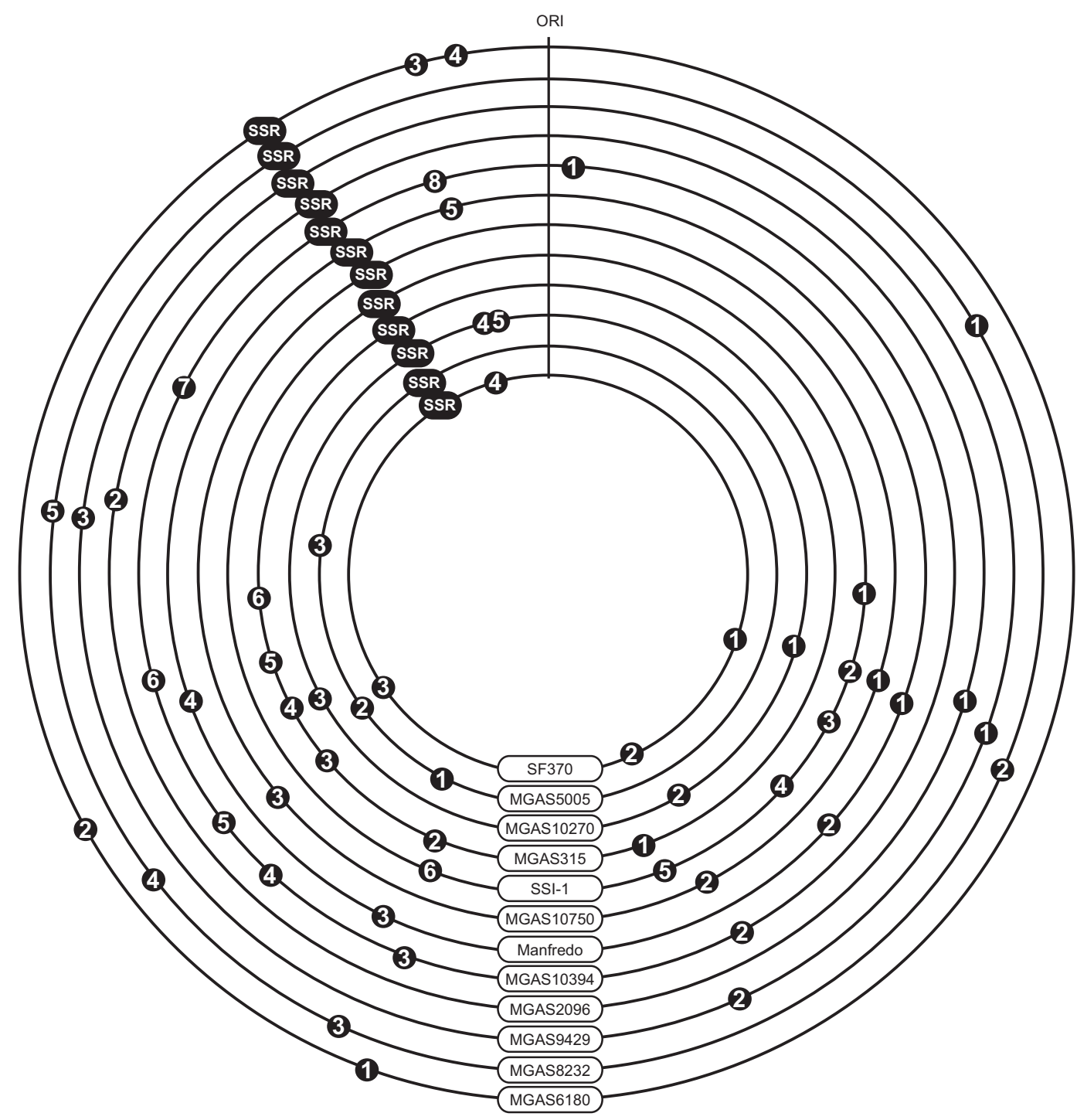

Figure 3

Location of the SSRs along the twelve S. pyogenes chromosome maps. All phagic and non-phagic SSRs revealed by cumulated TA skews are represented by black symbols. Phages are numbered sequentially according to their position along the chromosome, as already used in Beres et al. [37].

detected (Fig. 6). DNA sequencing indicate that the loss had occurred between smeZ (spy1998) and spy2050, corresponding to the region missing in the $\mathrm{M}$-protein-negative T11 within a variation of 200 bases on each side (Additional file 1 and Fig. 6). Since DNA was extracted from batch culture of ca $10^{10}-10^{11}$ colony forming units, spontaneous deletion occurred at a frequency estimated higher than $10^{-11}$.

\section{Discussion}

S. pyogenes is a highly versatile pathogen, which produces suppurative infections, toxin-related diseases, and delayed non-suppurative sequels $[2,33,34]$. A key element in its virulence is M-protein, a coil-coil peptidoglycan-attached polypeptide conferring anti-phagocytic properties. M-protein belongs to an $\mathrm{emm}$ and $\mathrm{emm}$-like gene family, and is characterized by a conserved C-terminal anchored in the cell wall, successively followed by conserved C-repeats, variable B-repeats and hypervariable A-repeats [30,31]. These variable repeats are responsible for $>125$ different M-serotypes [35].

Few M-serotypes are preferentially represented in certain disease strains [1]. Recently, serotype M1 was associated with pharyngitis and invasive diseases [26], M12 with pharyngitis [36] M3 with streptococcal toxic shock syn- 


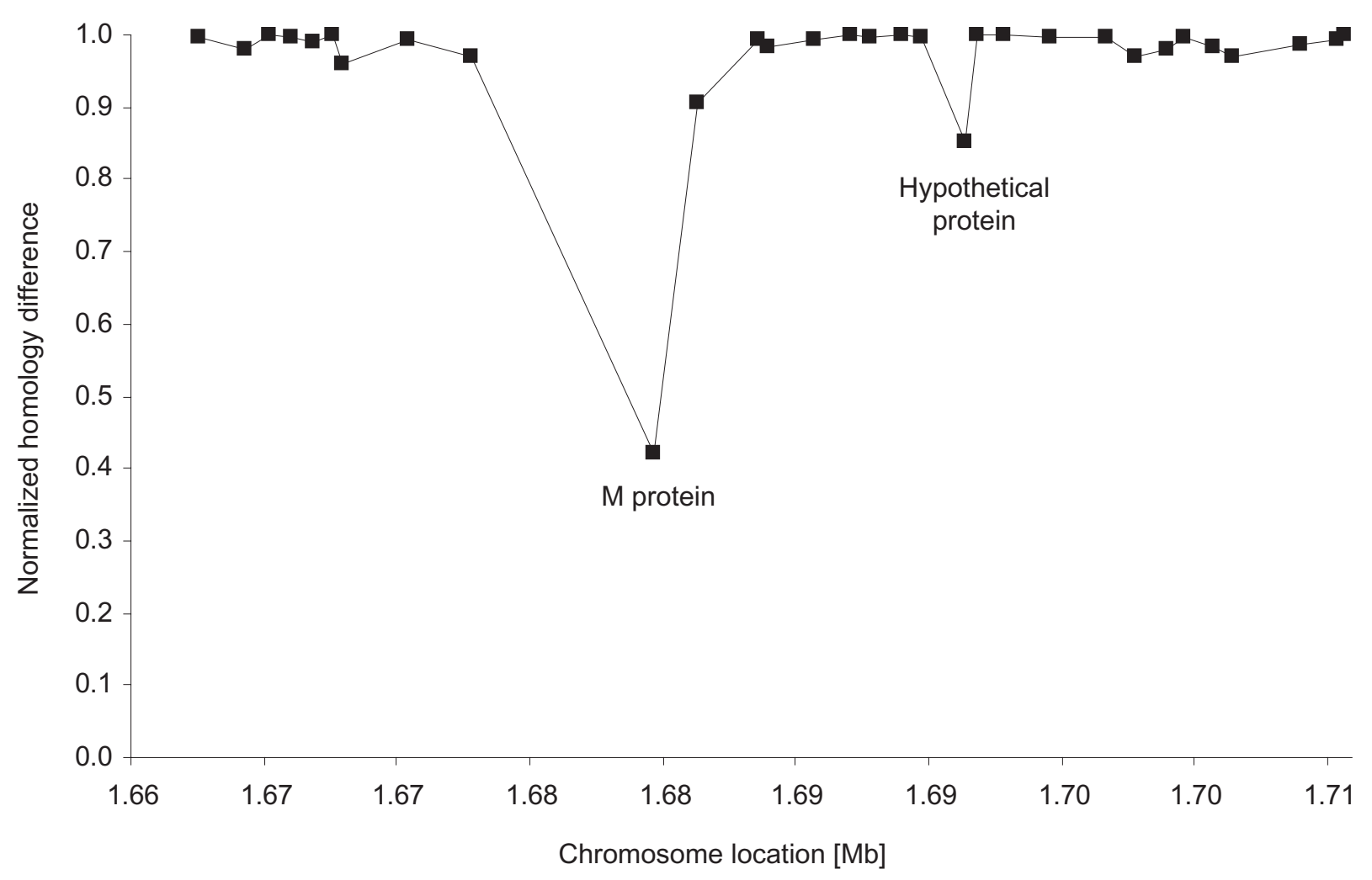

Figure 4

Similarity comparison of the core 3 I proteins present in all the non-phagic 47-kb SSRs of all strains, and missing in the M-protein-negative group A streptococcus TII. SF370 proteins are compared with proteins of all other genomes present in Table I. Protein Blast scores for the three genomes were averaged and normalized to the score of $\mathrm{MI}$ versus itself (normalized score of I). M protein type I (spy20I8) showed a major difference in its amino acid composition among strains.

drome [37-39], M6 with pharyngitis and macrolide-resistance due to the mefA gene [27], M5 and M18 with acute rheumatic fever $[40,41]$, and M28 with puerperal fever $[28,29]$. Yet, M-protein alone does not account for the whole spectrum of $S$. pyogenes infections. Up to 40 additional virulence genes are involved, which are encoded either on the streptococcal core chromosome or on prophages or transposons inserted in it [26].

Lately researchers analysed the genomic peculiarities of specific epidemic $S$. pyogenes strains, and compared them to collections of epidemiologically-related and unrelated isolates [26,27,29,37-40]. All strains exhibited a highly conserved core genome constituted of ca. $1.7 \mathrm{Mb}$, with a 38.4-38.7\% G+C content, and a high ( $\geq 90 \%)$ nucleotide similarity. In addition, epidemiologically-related strains presented similar assortments of horizontally-acquired genetic elements, including mostly - but not exclusively prophages that carried super-antigens, surface adhesins and sometimes antibiotic (macrolides)-resistance genes [27]. One salient example is the region of divergence RD2 recently described in a puerperal fever-related serotype M28 S. pyogenes strain $[28,29]$. RD2 is a large insert that is absent from other $S$. pyogenes serotypes, but was found in Streptococcus agalactiae, which also colonizes the female genital tract and can produce neonatal infections. RD2 encodes a transposase as well as surface adhesins that are involved in adherence to genito-urinary mucosal cells [28]. Thus, it is likely to be an acquired element that is responsible for the niche-related puerperal fever produced by the serotype M28 and related strains.

Ferretti et al. [26] showed that serotype M1 strain SF370 carried 43 putative virulence genes, of which 34 (79\%) are located on the core genome and $9(21 \%)$ on prophages. Comparative genomics indicated that the virulence genes of the core chromosome are highly conserved in the sequenced strains, and thus are likely to provide $S$. pyogenes 


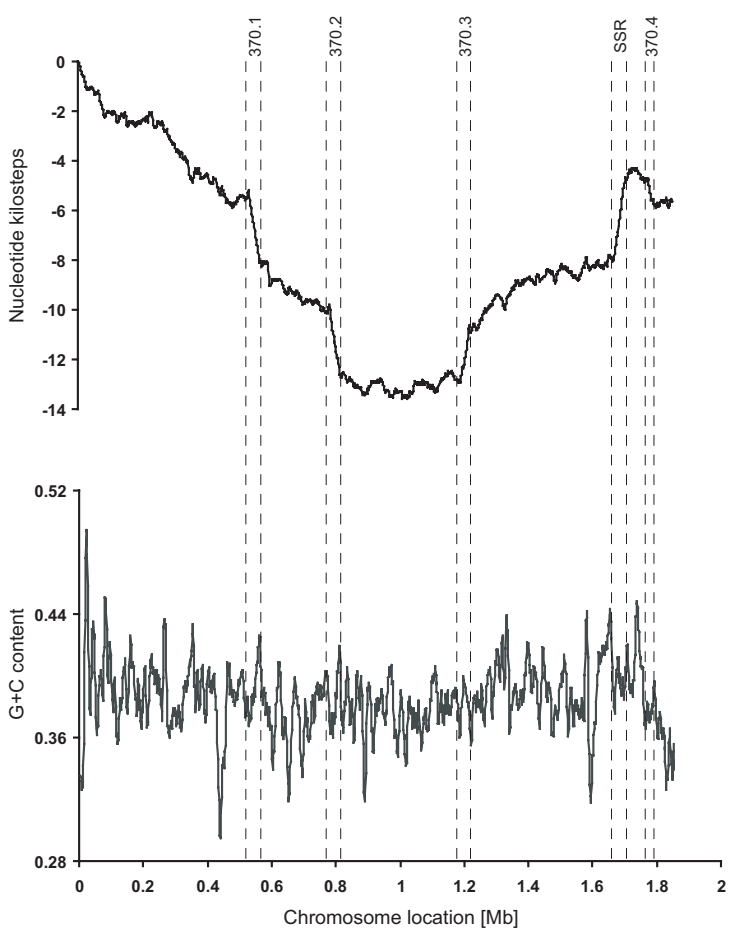

Figure 5

Comparison of TA skew (A) and $G+C$ content (B) of S. pyogenes SF370. SSR positions in the TA skew as well as in the $\mathrm{G}+\mathrm{C}$ content are shown using dashed lines.

with its basal virulence capability. In contrast, acquired virulence genes are variable and are likely to afford disease specificity [42-44]. The present results add supplementary arguments to the critical role of horizontally acquired genes in the evolution of bacterial pathogens. Indeed the major virulence genes considered species-specific of $S$. pyogenes, are located on a non-phagic $47-\mathrm{kb}$ SSR that carries features of a stabilized pathogenicity island [7-9].

Because of its high inter-strain homology, the evolutionary history of the non-phagic 47-kb SSR is not easy to reconstruct. However, a few hallmarks are apparent. First, the fact that it carries species-specific virulence factors - e.g. M-protein - indicates that it was acquired before the $S$. pyogenes speciation. Second, since it shares the same chromosomal location in all the sequenced strains, it was probably present in the genome before the acquisition of most prophages and other mobile elements, which vary in different strains. Third, since it is highly conserved among all sequenced strains, except for the anti-phagocytic M-protein, it was probably acquired only at a very few occasions, and further evolved different M-protein serotypes due to the immunologic pressure of the host. Eventually, the fact that it carries an identical set of 31 ORFs in all the strains, plus some additional genes in few isolates, suggest that it has further evolve by gene acquisition in these particular strains.
The current relatively large $47-\mathrm{kb}$ SSR is probably difficult to mobilize. This is supported by the fact that the loss of the element occurs neither between direct repeats nor at the Lys-tRNA locus, although the Lys-tRNA gene might have been the primordial insertion site in the chromosome. In pathogenicity islands conferring selective advantages to their host, all elements promoting island excision are progressively lost, leading to their stabilization in the bacterial chromosome [10]. An additional selective advantage conferred by the $47-\mathrm{kb}$ SSR might be the presence of several or all components of a hexose and a dipeptide importer, respectively. Indeed, the dipeptide permease was shown to contribute to bacterial growth and to expression of crucial virulence factors [31].

The high inter-strain conservation and the stability of the 47-kb SSR reflect its ancient acquisition. Nevertheless, accidental loss, probably by RecA-mediated recombination, is possible as supported experimentally, and might be favored by the presence of the direct repeats flanking the 47-kb SSR. The existence of such M-protein-negative strains might be underestimated, since routine identification of $S$. pyogenes determines only the presence of group A polysaccharide, ignoring the presence of M-protein [45]. Thus, it raises several important issues. First for taxonomy, because it is assumed that all group A polysaccharide streptococci carry the M-protein. Second for pathogenesis, because it would be relevant to know the $S$. pyogenes ancestor and how it acquired the M-protein gene. Finally for vaccine development, because a strategy targeting the products encoded by the 47 -kb SSR, e.g. M-protein, might select strains having lost the whole region, thus generating M-protein-negative strains that still carry prophageencoded toxins and adhesin genes.

\section{Conclusion}

Using the cumulative TA skew - a naïve method measuring biases in nucleotide composition - for the first time in this purpose, we could point to all known prophages of the twelve $S$. pyogenes sequenced chromosomes. Moreover, we showed that a region with similar biases, but not identified as a phage, is shared by all the strains, and concentrates one quarter of the known pathogenicity genes in about $50 \mathrm{~kb}$. Missing in at least one natural isolate and experimentally excisable at a very low frequency, this putative ancient pathogenicity island may have been acquired before $S$. pyogenes speciation, and subsequently become stabilized. Taken together, these results may allow to discover new genes involved in pathogenicity, and reinforce the importance of mobile regions on the evolution of pathogenicity in bacteria.

\section{Methods}

\section{Nucleotide sequences and genometric analyses}

Full genome sequences and annotation files of 12 currently sequenced $S$. pyogenes strains (Table 1 ) were 


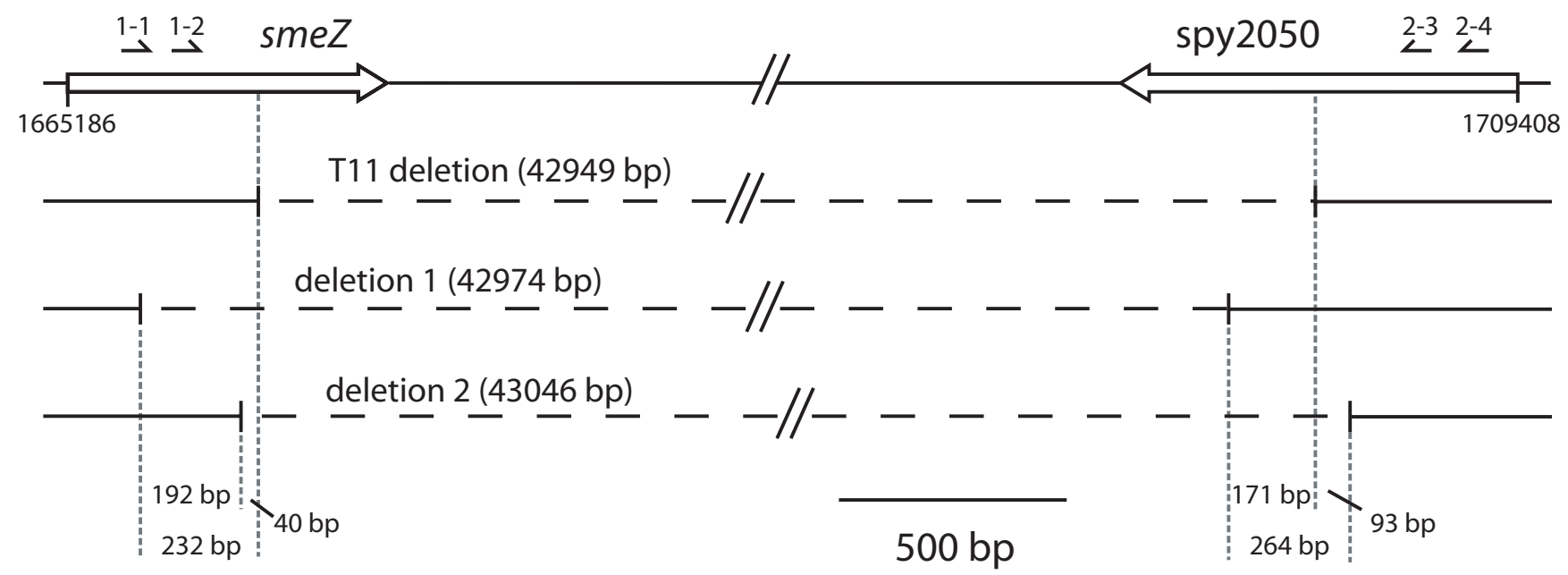

\section{Figure 6}

Spontaneous excision of MI S. pyogenes SF370. Mitogenic exotoxin Z (smeZ/spyl 998) and putative PTS system enzyme IIC component (spy2050) are the two coding genes where the boundaries for the natural isolate of M-protein-negative group A streptococcus TII can be found (TII deletion). In two out of four individual cycled cultures, an amplicon compatible with the excision of most part of the 47-kb SSR element was detected as shown by the two deletions (deletion I and deletion 2). Both amplicons were $200 \mathrm{bp}$ apart from the boundaries of the natural TII isolates. The region defined by the TA skew analysis starts 4520 bp upstream of the 5 '-end of smeZ, and ends 835 bp downstream of the 3' end of spy2050 (see additional file I). Oligonucleotides SVCI-I, SVCI-2, SVC2-3, SVC2-4 are represented above the genes. A 0.5-kb scale is indicated.

retrieved from the NBCI database $[26,27,29,36,37,39-$ $41,44]$.

We used the algorithms described in $[17,19]$ and implemented in the Genometrician's Scooter and in Comparative Genometrics [20] to investigate along raw chromosome sequences local biases of Gs and Cs, or Ts and As. First GC- and TA-skew values measuring the $\mathrm{G}$ and $\mathrm{T}$ excesses are determined for each $1-\mathrm{kb}$ window. Next, cumulative GC- or TA-values are calculated for a window $i$ by summing to its skew value $S k_{i}$ all preceding ones from $S k_{1}$ to $S k_{i-1}$. Finally, a cumulative curve is drawn by plotting to each position of window center the cumulative skew value [19].

\section{Bacteria and growth conditions}

Bacterial strains included the sequenced M1 S. pyogenes SF370 (ATCC 700294) [26], and a natural group A streptococcal isolate presenting a M-protein-negative serotype T11 [32]. Bacteria were identified at the species level by standard diagnosis methods including ribotyping and Acarbohydrate and M-protein typing [1,45]. They were grown without aeration in brain heart infusion broth (BHI; Oxoid Ltd, Hampshire, England) at $37^{\circ} \mathrm{C}$, under a $5 \% \mathrm{CO}_{2}$ atmosphere. Bacterial stocks were kept $-80^{\circ} \mathrm{C}$ in $10 \%$ (vol/vol) of glycerol.

\section{Detecting the loss of a putative 47-kb pathogenicity island} The genometric analysis identified a putative $47-\mathrm{kb}$ pathogenicity island encompassing the M-protein and other viru- lence genes (see Results section). We tested its possible loss in the M-protein-negative strain T11 and in strain SF370. Genomic DNA was extracted with the Qiagen DNeasy Tissue kit (Qiagen GmbH, Hilden, Germany). To detect a possible excision in strain T11 and determine its precise limits, we amplified DNA over the boundaries of the 47-kb segment by using converging primers synthesized by Microsynth (Balgach, Switzerland) targeting internal and flanking regions of the putative pathogenicity island. In addition to a series of control primer pairs directed to spy1999, spy2000 (open reading frame designation according to strain SF370) on one island side, and spy2039, spy2040, spy2043, spy2045, spy2047, and spy2049 on the other side, two oligonucleotides named SVC1-1 (5'-ACCAATCCGTTGTCCAAA) and SVC1-2 (5'-GGGTAATCCGGGCTATTCAG) were designed as forward primers hybridizing the smeZ gene (spy1998 in strain SF370), two others called SVC2-3 (5'-CAGGTGGTGGCACCTTTATT) and SVC2-4 (5'-GTTCCAGCAGAAGGTGAAGC) were selected to target spy2050 as backward primers. Utilizing the different primer combinations on the T11 genomic DNA, PCR cycling conditions consisted of 30 cycles at $94^{\circ} \mathrm{C}$ for $30 \mathrm{sec}, 52^{\circ} \mathrm{C}$ for $45 \mathrm{sec}$, and $72^{\circ} \mathrm{C}$ for 2.5 min, followed by a 10 -min delay period at $72^{\circ} \mathrm{C}$ after the last cycle. Detectable PCR-amplified fragments were first purified with the PCR DNA and gel band purification kit GFX (Amersham Biosciences, Buckinghamshire, England), and then sequenced by Synergen Biotech (Schlieren, Switzerland).

To detect spontaneous excisions of the 47-kb element in strain SF370, the bacterium was grown overnight to sta- 
tionary phase in four independent cultures cycled ten times in rich medium, from which DNA was prepared and processed for nested PCR according to Lesic et al [46] in order to detect very low amounts of DNA. Briefly, a first PCR was performed using primers SVC1-1 and SVC2-4, localized respectively 759 bp upstream and 531 bp downstream of the excision site predicted from protein M-negative strain T11 (see Results section). A second round of amplification was performed using the initial PCR mixture as template and primers internal to the first amplified sequence (SVC1-2 644 bp upstream and SVC2-3 281 bp downstream of the predicted excision site). Final amplification products were purified by agarose electrophoresis and sequenced as above.

\section{Abbreviations}

SSR: steep slope region; MRSA: methicillin-resistant Staphylococcus aureus.

\section{Authors' contributions}

CAHR designed the study. APa made the bioinformatic analysis, with a contribution by LG. FC, MH and MN performed the in vitro experiments, designed by PM and APo. APa, LG, PM, and CAHR drafted the manuscript. All authors took part in the interpretation of the results, improved the manuscript and approved its final version.

\section{Additional material}

\section{Additional file 1}

Gene content of the non-phagic 47-kb SSR of M1 S. pyogenes SF370. Click here for file

[http://www.biomedcentral.com/content/supplementary/14712164-10-198-S1.pdf]

\section{Acknowledgements}

We would like to thank Ms. Jana Normann, Rostock, for her high quality technical assistance, and the two anonymous reviewers for their suggestions. The work of M. Nakata and A. Podbielski was supported by DFG grant Po 39 I//2-2. CAH Roten was partially supported by a Swiss National Fund grant no. 3200-06537I.

\section{References}

I. Cunningham MW: Pathogenesis of group A streptococcal infections. Clin Microbiol Rev 2000, I3(3):470-5 I I.

2. McCormick JK, Yarwood JM, Schlievert PM: Toxic shock syndrome and bacterial superantigens: an update. Annu Rev Microbiol 200I, 55:77-104.

3. Kaneko J, Kimura T, Narita S, Tomita T, Kamio Y: Complete nucleotide sequence and molecular characterization of the temperate staphylococcal bacteriophage phiPVL carrying Panton-Valentine leukocidin genes. Gene 1998, 2I 5(I):57-67.

4. Clarke SC, Haigh RD, Freestone PP, Williams PH: Virulence of enteropathogenic Escherichia coli, a global pathogen. Clin Microbiol Rev 2003, I6(3):365-378.

5. McDaniel TK, Kaper JB: A cloned pathogenicity island from enteropathogenic Escherichia coli confers the attaching and effacing phenotype on E. coli K-I2. Mol Microbiol 1997, 23(2):399-407.

6. Mellies JL, Navarro-Garcia F, Okeke I, Frederickson J, Nataro JP, Kaper JB: espC pathogenicity island of enteropathogenic Escherichia coli encodes an enterotoxin. Infect Immun 200I, 69(I):315-324.

7. Hacker J, Blum-Oehler G, Muhldorfer I, Tschape H: Pathogenicity islands of virulent bacteria: structure, function and impact on microbial evolution. Mol Microbiol I997, 23(6): I089- 1097.

8. Hacker J, Hentschel U, Dobrindt U: Prokaryotic chromosomes and disease. Science 2003, 30 I(5634):790-793.

9. Oelschlaeger TA, Dobrindt U, Janke B, Middendorf B, Karch H, Hacker J: Analysis of pathogenicity islands of STEC. Methods Mol Med 2003, 73:99-I I 2.

10. Hacker J, Kaper JB: Pathogenicity islands and the evolution of microbes. Annu Rev Microbiol 2000, 54(1):641-679.

II. Katayama Y, Ito T, Hiramatsu K: A new class of genetic element, staphylococcus cassette chromosome mec, encodes methicillin resistance in Staphylococcus aureus. Antimicrob Agents Chemother 2000, 44(6): I549-I555.

12. Ito T, Katayama Y, Asada K, Mori N, Tsutsumimoto K, Tiensasitorn C, Hiramatsu K: Structural comparison of three types of staphylococcal cassette chromosome mec integrated in the chromosome in methicillin-resistant Staphylococcus aureus. Antimicrob Agents Chemother 200I, 45(5): I 323-I336.

13. Ma XX, Ito T, Tiensasitorn C, Jamklang M, Chongtrakool P, BoyleVavra S, Daum RS, Hiramatsu K: Novel type of staphylococcal cassette chromosome mec identified in communityacquired methicillin-resistant Staphylococcus aureus strains. Antimicrob Agents Chemother 2002, 46(4): I I47-I I 52.

14. Kollef $\mathrm{MH}$, Micek ST: Methicillin-resistant Staphylococcus aureus: a new community-acquired pathogen? Curr Opin Infect Dis 2006, 19(2): $161-168$.

15. Guy L: Identification and characterization of pathogenicity and other genomic islands using base composition analyses. Future Microbiol 2006, I(3):309-316.

16. Lawrence JG, Ochman H: Amelioration of Bacterial Genomes: Rates of Change and Exchange. J Mol Evol I997, 44(4):383-397.

17. Grigoriev A: Analyzing genomes with cumulative skew diagrams. Nucleic Acids Res I998, 26( I 0):2286-2290.

18. Lobry JR: Asymmetric substitution patterns in the two DNA strands of bacteria. Mol Biol Evol 1996, I3(5):660-665.

19. Roten CA, Gamba P, Barblan JL, Karamata D: Comparative Genometrics (CG): a database dedicated to biometric comparisons of whole genomes. Nucleic Acids Res 2002, 30(I): | 42- | 44.

20. Comparative Genometrics Database [http://www.unil.ch/com parativegenometrics/]

21. Bennett WR: Introduction to computer applications for nonscience students (BASIC). Englewood Cliffs, N.J.: Prentice-Hall; 1976.

22. Kreikemeyer B, Mclver KS, Podbielski A: Virulence factor regulation and regulatory networks in Streptococcus pyogenes and their impact on pathogen-host interactions. Trends Microbiol 2003, I I(5):224-232.

23. Podbielski A, Woischnik M, Leonard BA, Schmidt KH: Characterization of nra, a global negative regulator gene in group $A$ streptococci. Mol Microbiol 1999, 3 I (4): I05 I-I 064.

24. Podbielski A, Woischnik M, Pohl B, Schmidt KH: What is the size of the group A streptococcal vir regulon? The Mga regulator affects expression of secreted and surface virulence factors. Med Microbiol Immunol (Berl) 1996, I85(3): I7I-I8I.

25. Guy L, Karamata D, Moreillon P, Roten CA: Genometrics as an essential tool for the assembly of whole genome sequences: the example of the chromosome of Bifidobacterium longum NCC2705. BMC Microbiol 2005, 5:60.

26. Ferretti JJ, McShan WM, Ajdic D, Savic DJ, Savic G, Lyon K, Primeaux C, Sezate S, Suvorov AN, Kenton S, et al:: Complete genome sequence of an MI strain of Streptococcus pyogenes. Proc Natl Acad Sci USA 200I, 98(8):4658-4663.

27. Banks DJ, Porcella SF, Barbian KD, Beres SB, Philips LE, Voyich JM, DeLeo FR, Martin JM, Somerville GA, Musser JM: Progress toward characterization of the group A Streptococcus metagenome: complete genome sequence of a macrolide-resistant serotype M6 strain. J Infect Dis 2004, I90(4):727-738.

28. Green NM, Beres SB, Graviss EA, Allison JE, McGeer AJ, Vuopio-Varkila J, LeFebvre RB, Musser JM: Genetic diversity among type 
emm28 group A Streptococcus strains causing invasive infections and pharyngitis. J Clin Microbiol 2005, 43(8):4083-409।

29. Green NM, Zhang S, Porcella SF, Nagiec MJ, Barbian KD, Beres SB LeFebvre RB, Musser JM: Genome sequence of a serotype M28 strain of group A Streptococcus: potential new insights into puerperal sepsis and bacterial disease specificity. J Infect Dis 2005, I 92(5):760-770.

30. Fischetti VA: Streptococcal M protein: molecular design and biological behavior. Clin Microbiol Rev 1989, 2(3):285-3I4.

31. Podbielski A, Weber-Heynemann J, Cleary PP: Immunoglobulinbinding FcrA and Enn proteins and M proteins of group $A$ streptococci evolved independently from a common ancestral protein. Med Microbiol Immunol (Berl) 1994, 183(I):33-42.

32. Podbielski A, Schnitzler N, Beyhs P, Boyle MD: M-related protein (Mrp) contributes to group A streptococcal resistance to phagocytosis by human granulocytes. Mol Microbiol 1996, 19(3):429-44I.

33. Muller N, Kroll B, Schwarz MJ, Riedel M, Straube A, Lutticken R, Reinert RR, Reineke T, Kuhnemund O: Increased titers of antibodies against streptococcal MI 2 and $M I 9$ proteins in patients with Tourette's syndrome. Psychiatry Res 200I, I0I(2):187-193.

34. Loiselle CR, Wendlandt JT, Rohde CA, Singer HS: Antistreptococcal, neuronal, and nuclear antibodies in Tourette syndrome. Pediatr Neurol 2003, 28(2): I 19-1 25.

35. Facklam RF, Martin DR, Lovgren M, Johnson DR, Efstratiou A, Thompson TA, Gowan S, Kriz P, Tyrrell G], Kaplan E, et al.: Extension of the Lancefield classification for group A streptococci by addition of 22 new $M$ protein gene sequence types from clinical isolates: emm/03 to emm/24. Clin Infect Dis 2002, 34(I):28-38.

36. Beres SB, Richter EW, Nagiec MJ, Sumby P, Porcella SF, DeLeo FR, Musser JM: Molecular genetic anatomy of inter- and intraserotype variation in the human bacterial pathogen group $A$ Streptococcus. Proc Natl Acad Sci USA 2006, 103( 1 8):7059-7064.

37. Beres SB, Sylva GL, Barbian KD, Lei B, Hoff JS, Mammarella ND, Liu MY, Smoot JC, Porcella SF, Parkins LD, et al:: Genome sequence of a serotype M3 strain of group A Streptococcus: phageencoded toxins, the high-virulence phenotype, and clone emergence. Proc Natl Acad Sci USA 2002, 99( I 5): 10078- 10083.

38. Beres SB, Sylva GL, Sturdevant DE, Granville CN, Liu M, Ricklefs SM, Whitney AR, Parkins LD, Hoe NP, Adams GJ, et al.: Genome-wide molecular dissection of serotype M3 group A Streptococcus strains causing two epidemics of invasive infections. Proc Natl Acad Sci USA 2004, I0I(32): I I833-I I 838.

39. Nakagawa I, Kurokawa K, Yamashita A, Nakata M, Tomiyasu Y, Okahashi N, Kawabata S, Yamazaki K, Shiba T, Yasunaga T, et al: Genome sequence of an M3 strain of Streptococcus pyogenes reveals a large-scale genomic rearrangement in invasive strains and new insights into phage evolution. Genome Res 2003, I3(6A): 1042-1055.

40. Smoot JC, Barbian KD, Van Gompel J], Smoot LM, Chaussee MS, Sylva GL, Sturdevant DE, Ricklefs SM, Porcella SF, Parkins LD, et al.: Genome sequence and comparative microarray analysis of serotype MI 8 group A Streptococcus strains associated with acute rheumatic fever outbreaks. Proc Natl Acad Sci USA 2002, 99(7):4668-4673.

41. Holden MTG, Scott A, Cherevach I, Chillingworth T, Churcher C, Cronin A, Dowd L, Feltwell T, Hamlin N, Holroyd S, et al.: The complete genome of an acute rheumatic fever (ARF) associated serotype M5 Streptococcus pyogenes strain Manfredo. J Bacteriol 2006, I89(4): I473-1477.

42. Banks DJ, Beres SB, Musser JM: The fundamental contribution of phages to GAS evolution, genome diversification and strain emergence. Trends Microbiol 2002, I 0(I I):515-52I.

43. Musser JM, DeLeo FR: Toward a genome-wide systems biology analysis of host-pathogen interactions in group A Streptococcus. Am J Pathol 2005, 167(6): | 46 |- | 472.

44. Sumby P, Porcella SF, Madrigal AG, Barbian KD, Virtaneva K, Ricklefs SM, Sturdevant DE, Graham MR, Vuopio-Varkila J, Hoe NP, et al.: Evolutionary origin and emergence of a highly successful clone of serotype MI group A Streptococcus involved multiple horizontal gene transfer events. J Infect Dis 2005, 192(5):77|-782.

45. Bourbeau PP: Role of the microbiology laboratory in diagnosis and management of pharyngitis. I Clin Microbiol 2003, 4 I (8):3467-3472.
46. Lesic B, Bach S, Ghigo JM, Dobrindt U, Hacker J, Carniel E: Excision of the high-pathogenicity island of Yersinia pseudotuberculosis requires the combined actions of its cognate integrase and Hef, a new recombination directionality factor. Mol Microbiol 2004, 52(5): I337-1348.
Publish with Biomed Central and every scientist can read your work free of charge

"BioMed Central will be the most significant development for disseminating the results of biomedical research in our lifetime. "

Sir Paul Nurse, Cancer Research UK

Your research papers will be:

- available free of charge to the entire biomedical community

- peer reviewed and published immediately upon acceptance

- cited in PubMed and archived on PubMed Central

- yours - you keep the copyright 